\title{
Enhanced biocompatibility and osteogenic potential of mesoporous magnesium silicate/ polycaprolactone/wheat protein composite scaffolds
}

This article was published in the following Dove Press journal:

International Journal of Nanomedicine

\author{
Yun Gyeong Kang' \\ Jie $\mathrm{Wei}^{2}$ \\ JiWon Shin' \\ Yan $\mathrm{Ru} \mathrm{Wu}^{3}$ \\ Jiacan $\mathrm{Su}^{4}$ \\ Young Shik Park ${ }^{5}$ \\ Jung-Woog Shin ${ }^{1,3,6}$
}

'School of Biomedical Engineering, Inje University, Gimhae, Republic of Korea; ${ }^{2}$ Key Laboratory for Ultrafine Materials of Ministry of Education, East China University of Science and Technology, Shanghai, China; ${ }^{3}$ Department of Health Science and Technology, Inje University, Gimhae, Republic of Korea; ${ }^{4}$ Department of Orthopaedics, Changhai Hospital, Second Military Medical University, Shanghai, China; ${ }^{5}$ School of Biological Science, Inje University, Gimhae, Republic of Korea; ${ }^{6}$ Cardiovascular and Metabolic Disease Center/ Institute of Aged Life Redesign/ UHARC, Inje University, Gimhae, Republic of Korea
Correspondence: Jung-Woog Shin ORCID ID: 0000-0003-1047-987| Rm \#309, BLDG-A, Inje University, 197, Inje-ro, Gimhae-si,

Gyeongsangnam-do, 50834,

Republic of Korea

$\mathrm{Tel}+82553203317$

Fax +82 553273292

Email biomechshin@gmail.com
Background: Successful bone tissue engineering using scaffolds is primarily dependent on the properties of the scaffold, including biocompatibility, highly interconnected porosity, and mechanical integrity.

Methods: In this study, we propose new composite scaffolds consisting of mesoporous magnesium silicate (m_MS), polycaprolactone (PCL), and wheat protein (WP) manufactured by a rapid prototyping technique to provide a micro/macro porous structure. Experimental groups were set based on the component ratio: (1) WP0\% (m_MS:PCL:WP=30:70:0 weight per weight; w/w); (2) WP15\% (m_MS:PCL:WP =30:55:15 w/w); (3) WP30\% (m_MS:PCL:WP =30:40:30 w/w).

Results: Evaluation of the properties of fabricated scaffolds indicated that increasing the amount of WP improved the surface hydrophilicity and biodegradability of m_MS/PCL/WP composites, while reducing the mechanical strength. Moreover, experiments were performed to confirm the biocompatibility and osteogenic differentiation of human mesenchymal stem cells (MSCs) according to the component ratio of the scaffold. The results confirmed that the content of WP affects proliferation and osteogenic differentiation of MSCs. Based on the last day of the experiment, ie, the 14th day, the proliferation based on the amount of DNA was the best in the WP30\% group, but all of the markers measured by PCR were the most expressed in the WP15\% group. Conclusion: These results suggest that the m_MS/PCL/WP composite is a promising candidate for use as a scaffold in cell-based bone regeneration.

Keywords: mesoporous magnesium silicate, wheat protein, scaffold, bone tissue engineering, osteogenic differentiation

\section{Introduction}

Bone tissue engineering is aimed at treating injured bone tissues by inducing regeneration. Three major factors should be considered in tissue engineering: cell sources, scaffolds, and environmental factors, including physical and secreted factors. ${ }^{1.2}$ Effective induction of tissue regeneration requires the development and combination of these three elements.

Scaffolds must fulfill various physical and biological requirements to provide a platform for cell adhesion, function, and transplantation. Scaffolds are prepared with their physical properties taken into consideration, including chemical properties, such as surface molecules and degradation patterns, as well as structural properties, such as pore size, orientation, and strength. ${ }^{2-4}$ Rapid prototyping techniques have attracted a great deal of attention with regard to overcoming the drawbacks of conventional 
techniques, such as particulate leaching, ${ }^{5}$ gas foaming, ${ }^{6}$ phase separation, ${ }^{7}$ and freeze drying, ${ }^{8}$ which do not provide controllable pore size, pore geometry, and pore interconnectivity.

With regard to materials for 3-dimensional (3-D) plotting, polycaprolactone (PCL) is a commonly used material in bone tissue engineering. ${ }^{9}$ PCL is biodegradable, with a relatively long degradation time depending on its molecular weight, and is relatively easy to handle. However, the hydrophobic nature of the surface is known to interfere with initial attachment of the cells and subsequent growth. ${ }^{10}$

Various modification techniques have been developed to overcome these surface characteristics of PCL scaffolds, including coating or blending PCL with other biocompatible materials, such hydroxyapatite. ${ }^{11}$ Moreover, to overcome the limitations of classical biodegradable polymers, various natural polymers have been developed from agricultural products, such as starches and plant oils. ${ }^{12,13}$ Wheat protein (WP) is one of the most promising polymer materials, and is relatively abundant in various amino acids (eg, glycine, serine, and proline) that are similar to those in collagen proteins in natural bone. ${ }^{14-16} \mathrm{Kim}$ and $\mathrm{Kim}^{17}$ used WP for surface modification to increase the hydrophilicity of the polymer. Owing to its abundant nutrients and chemical properties, WP is a good candidate material for use in bone tissue engineering.

Magnesium has been shown to be a suitable biomaterial for orthopedic applications, eg, in biodegradable magnesium alloy and magnesium-containing bioactive glasses. ${ }^{18-20}$ Magnesium degrades without toxicity in the body and increases osteoconductivity in vivo, enabling complete bone regeneration at the implant site. ${ }^{21}$ In addition, the proliferation and gene expression of osteogenic markers have been shown to be increased in cells exposed to magnesium in vitro. ${ }^{22}$ Magnesium silicate (MS) bioceramics have been used in bone tissue engineering because of their osteogenic properties, significant bone-like apatite formation ability, and excellent bioactivity. ${ }^{23,24}$ In addition, the application of mesoporous materials with a pore size of 2-50 $\mathrm{nm}$ in bone tissue regeneration has increased significantly due to the characteristics of the material, including uniform pore size and high specific surface area. ${ }^{14,25,26}$

Although the benefits of each material are well understood, there have been few studies on WP-based composites for application of biomaterials to bone regeneration. Moreover, there have been no reports regarding the possibility of bone tissue regeneration according to the combination of WP, PCL, and MS. To address some of these unresolved problems, this study proposes a novel porous composite scaffold composed of PCL, WP, and mesoporous magnesium silicate (m_MS). In addition, we investigated the influence of WP content on the properties of m_MS/PCL/WP composites.
We used the rapid prototyping technique to provide a 3-D lattice structure with well-interconnected macropores, and to provide a mesoporous structure using m-MS. We performed a number of analyses to characterize the proposed scaffolds, such as examinations of morphology, mechanical stiffness, hydrophilicity, and degradability of composite scaffolds. In addition, cell proliferation and osteogenic differentiation using human mesenchymal stem cells (MSCs) were investigated to demonstrate further the cytocompatibility of the novel m_MS/PCL/WP composite scaffolds.

\section{Materials and methods}

\section{Fabrication of scaffolds}

Amorphous m_MS was synthesized by the sol-gel technique and was provided by East China University of Science and Technology (Shanghai, China). ${ }^{14}$ PCL (MW 43,000-50,000) and WP were purchased from Polyscience, Inc. (Warrington, PA, USA) and Tokyo Chemical Industry Co. Ltd (Tokyo, Japan), respectively. Each material was mixed according to the component ratio (weight per weight; w/w) of each group, and scaffolds were fabricated by a rapid prototyping technique. The experimental groups were divided into 3 groups according to the weight ratio of PCL and WP, except for m-MS containing the same amount in all groups as follows: (1) WP0\% (m_MS:PCL:WP =30:70:0 w/w); (2) WP15\% (m_MS:PCL:WP=30:55:15 w/w); (3) WP30\% (m_MS:PCL:WP =30:40:30 w/w).

\section{Characterization of $\mathrm{m}-\mathrm{MS} / \mathrm{PCL} / \mathrm{WP}$ scaffolds}

The surfaces of scaffolds were examined by scanning electron microscopy (SEM) (S3500N; Hitachi, Tokyo, Japan). The scaffolds were sputter coated with gold (Au).

In addition, the contact angle of each scaffold was measured using a contact angle analyzer (Phoenix 250; Surface \& Electro Optics, Gyeonggi-do, Korea) and Image Pro 300 software (Surface \& Electro Optics) to confirm the hydrophilicity. Briefly, they were measured at $60 \mathrm{~s}$ after dropping water droplets at three different spots on each sample.

To evaluate mechanical stiffness, compression tests were performed on the scaffolds using a Micro-load System (R \& B Inc., Daejeon, Korea) at room temperature ( $\mathrm{n}=5$ for each group). Each fabricated scaffold was cut to dimensions of $6 \times 6 \times 5.5 \mathrm{~mm}^{3}$. The displacement rate was set as $1 \mathrm{~mm} / \mathrm{min}$.

\section{In vitro degradability of $\mathrm{m} \_\mathrm{MS} / \mathrm{PCL} / \mathrm{WP}$ scaffolds}

The in vitro degradation behaviors of scaffolds were assessed by measuring weight loss. Each sample was soaked in PBS 
( $\mathrm{pH}=7.4$ ) at $37^{\circ} \mathrm{C}$. The solution was set to $200 \mathrm{~mL} / \mathrm{g}$ of sample. The bottle containing scaffold with PBS solution was placed in a shaking water bath $\left(37^{\circ} \mathrm{C}, 80 \mathrm{rpm}\right)$. The specimens were taken out at the designated point of times $(1,3,7,14$, 21 , and 28 days). After wiping off the surface moisture, the specimens were weighed while wet. After measurement, they were washed again with distilled water, dried in an oven at $37^{\circ} \mathrm{C}$ for $24 \mathrm{~h}$, and weighed again. Based on all measurements, the weight loss ratio and water absorption ratio were calculated according to the following equation:

$$
\begin{gathered}
\text { Weight loss ratio }(\%)=\frac{W_{0}-W_{\mathrm{d}}}{W_{0}} \times 100 \\
\text { Water absorption ratio }(\%)=\frac{W_{\mathrm{w}}-W_{0}}{W_{0}} \times 100
\end{gathered}
$$

where $W_{0}$ is the initial weight, $W_{\mathrm{d}}$ is the dried sample weight, and $W_{\mathrm{w}}$ is the wet sample weight. The value of weight loss ratio indicates how much the sample has degraded within a given time. The water absorption ratio indicates the amount of PBS contained in the sample, indicating the degree of hydrophilicity.

\section{In vitro bioactivity of $\mathrm{m} \_\mathrm{MS} / \mathrm{PCL} / \mathrm{WP}$ scaffolds in simulated body fluid}

The in vitro bioactivity of each scaffold was determined by soaking the samples in simulated body fluid ( $\mathrm{SBF}, \mathrm{pH}=7.4$; Biosesang, Gyeonggi-do, Korea) at $37^{\circ} \mathrm{C}$ for 7 days. The solution volume/specimen weight ratio was $20 \mathrm{~mL} / \mathrm{g}$. After soaking for 7 days, the surface morphology of the samples before and after immersion in SBF were confirmed by SEM.

\section{Cytotoxicity test}

Before cytotoxicity test, each scaffold $\left(6 \times 6 \times 5.5 \mathrm{~mm}^{3}\right)$ was sterilized in $70 \%$ ethanol for $3 \mathrm{~h}$, washed in deionized water, and then irradiated with ultraviolet (UV) for $30 \mathrm{~min}$. Each scaffold was immersed in culture medium $(100 \mathrm{mg} / \mathrm{mL})$ consisting of DMEM (Thermo Fisher Scientific, Waltham, MA, USA) supplemented with 10\% fetal bovine serum (FBS; Thermo Fisher Scientific), $100 \mathrm{U} / \mathrm{mL}$ penicillin (Thermo Fisher Scientific), and $100 \mathrm{mg} / \mathrm{mL}$ streptomycin (Thermo Fisher Scientific) at $37^{\circ} \mathrm{C}$ for $24 \mathrm{~h}$. The extracts were collected for cytotoxicity test. Phenol (1\%) was used as positive control and PCL and DMEM as negative control, respectively.

Mouse fibroblast-like cells (L929 cells; Korean Cell Line Bank, Seoul, Korea) were seeded in 48-well culture plate $\left(5 \times 10^{4}\right.$ cells $\left./ \mathrm{cm}^{2}\right)$ and cultured for $24 \mathrm{~h}$ with each extract.
Then a MTT (Roche Applied Science, Indianapolis, IN, USA) assay was carried out to quantify the amount of viable cells. Briefly, MTT labeling reagent was added to each well and the plates were incubated for $4 \mathrm{~h}$ at $37^{\circ} \mathrm{C}$. Solubilization solution was then added and incubated overnight at $37^{\circ} \mathrm{C}$. The OD of each well was measured at $570 \mathrm{~nm}$ in a microplate reader (Multiskan EX; Thermo Fisher Scientific).

\section{MSC culture and seeding}

Before seeding MSCs on the scaffold, the surface of sterilized scaffolds was treated with $10 \mu \mathrm{g} / \mathrm{mL}$ fibronectin (SigmaAldrich Co, St Louis, MO, USA) in PBS with $0.1 \%$ gelatin (Sigma-Aldrich $\mathrm{Co}$ ) for $2 \mathrm{~h}$ to promote cell adhesion.

Human bone marrow-derived MSCs were purchased from Lonza (Walkersville, MD, USA) and cultured according to the manufacturer's protocol up to passage \#4. MSCs were seeded onto each fibronectin-coated scaffold at a concentration of $1 \times 10^{6}$ cells $/ \mathrm{mL}$ using infiltration methods. Osteogenic differentiation of MSCs was induced in DMEM with low glucose (Thermo Fisher Scientific) containing $50 \mu \mathrm{g} / \mathrm{mL}$ L-ascorbic acid (Sigma-Aldrich Co), $10 \mathrm{mM} \beta$-glycerophosphate (Sigma-Aldrich Co), $10^{-7} \mathrm{M}$ dexamethasone (Sigma-Aldrich Co), 10\% FBS (Thermo Fisher Scientific), $100 \mathrm{U} / \mathrm{mL}$ penicillin (Thermo Fisher Scientific), and $100 \mathrm{mg} / \mathrm{mL}$ streptomycin (Thermo Fisher Scientific).

\section{Cell viability and morphology analysis}

To visualize cell viability and alignment, a live/dead viability assay (Thermo Fisher Scientific) was performed according to the manufacturer's instructions on day 7. A $1 \mathrm{~mL}$ aliquot of the assay solution containing $2 \mu \mathrm{L}$ EthD-1 (ethidium homodimer-1) and $0.5 \mu \mathrm{L}$ calcein AM was pipetted onto each cell-scaffold construct. After $30 \mathrm{~min}$ incubation at room temperature, the stained cells were observed using a confocal laser scanning microscope (LSM 510 META; Carl Zeiss, Jena, Germany). The excitation/emission filters were set at $488 / 530 \mathrm{~nm}$ to observe live (green) cells and at 530/580 nm to detect dead (red) cells.

\section{Cell proliferation}

To evaluate the proliferation of MSCs, DNA content was measured using a Quanti-iT PicoGreen ${ }^{\circledR}$ dsDNA Kit (Thermo Fisher Scientific). PicoGreen ${ }^{\circledR}$ dye binds to nucleic acids and then DNA concentration can be measured by determining the fluorescent activity. Triton X-100 (0.1\%) was added to the samples followed by centrifugation at $13,000 \mathrm{rpm}$ for $5 \mathrm{~min}$ at $4^{\circ} \mathrm{C}$. PicoGreen ${ }^{\circledR}$ reagent was added to each sample in 96-well plates, and samples were incubated for $5 \mathrm{~min}$ in the dark. 
The fluorescent emission intensity was measured at $520 \mathrm{~nm}$ using a multidetection microplate reader, Synergy HT (BioTek Instruments, Winooski, VT, USA).

\section{Alkaline phosphatase (ALP) activity}

The ALP activity was measured to study early differentiation of cells. Triton X-100 (0.1\%) was added to the samples, followed by centrifugation at $13,000 \mathrm{rpm}$ for $5 \mathrm{~min}$ at $4^{\circ} \mathrm{C}$. The substrate solution (Sigma-Aldrich Co) and alkaline buffer solution (Sigma-Aldrich $\mathrm{Co}$ ) were added to each sample at $37^{\circ} \mathrm{C}$ for $30 \mathrm{~min}$. After the reaction stopped, $1 \mathrm{~N} \mathrm{NaOH}$ solution was added to each sample. The samples were then transferred into 96-well plates, and the absorbance at $405 \mathrm{~nm}$ was measured using a microplate reader (Multiskan EX; Thermo Fisher Scientific).

\section{Quantitative real-time polymerase chain reaction (qRT-PCR)}

Quantitative real-time polymerase chain reaction (qRT-PCR) was conducted to detect the expression of bone-related genes (BMP2, BSP, COL1A1, RUNX2, and $O P N$ ) and $A C T B$ in the MSCs (Table 1). The housekeeping gene $A C T B$ was used as an internal control. Total RNA was purified using an RNeasy Mini Kit (Qiagen, Hilden, Germany) according to the manufacturer's instructions. RNA was preincubated with DNase I (Thermo Fisher Scientific), and reverse transcription was performed with a high-capacity RNA to cDNA kit (Thermo Fisher Scientific) according to the manufacturer's instructions. qRT-PCR was performed on cDNA using Power SYBR Green PCR Master Mix (Thermo Fisher Scientific). Data analysis was performed using a QuantStudio 3 Real-Time PCR System (Thermo Fisher Scientific) accord-

Table I Primers used for quantitative real-time polymerase chain reaction

\begin{tabular}{lll}
\hline Gene & $\begin{array}{l}\text { Forward }(\mathbf{F}) \text { and reverse (R) primer } \\
\left(\mathbf{5}^{\prime} \rightarrow \mathbf{3}^{\prime}\right)\end{array}$ & Accession no \\
\hline BMP2 & $\begin{array}{l}\text { (F) GCTGGTCACAGATAAGGCCA } \\
\text { (R) CAGCATCGAGATAGCACTGAGTTC }\end{array}$ & NM_00I200.3 \\
BSP & $\begin{array}{l}\text { (F) CAGAGGCAGAAAACGGCAAC } \\
\text { (R) TTGTTGTCTTCGAGGTGCCC }\end{array}$ & NM_004967.3 \\
COLIAI & $\begin{array}{l}\text { (F) CTGCACGAGTCACACCGGA } \\
\text { (R) AAGCCGAATTCCTGGTCTGG }\end{array}$ & NM_000088.3 \\
RUNX2 & $\begin{array}{l}\text { (F) TGAGATTTGTGGGCCGGAGTGG } \\
\text { OPN }\end{array}$ & NM_00I024630.3 \\
& $\begin{array}{l}\text { (F) GGAAAGCGGAGGGAGTTGAATGGTGC NM_000582.2 } \\
\text { (R) GGACTGCTTGTGGCTGTGGGTTTC }\end{array}$ \\
ACTB & $\begin{array}{l}\text { (F) CCAAAGTTCACAATGTGGC } \\
\text { (R) GATGGCAAGGGACTTCCTGT }\end{array}$ & NM_001101.3 \\
\hline
\end{tabular}

Abbreviations: $B M P 2$, bone morphogenetic protein 2; $B S P$, bone sialoprotein; COLIAI, collagen type I alpha I chain; RUNX2, runt-related transcription factor 2; OPN, osteopontin; ACTB, actin beta. ing to the $2^{-\Delta \Delta C t}$ method. qRT-PCR analyses were performed three times for each sample.

\section{Statistical analyses}

The significance of differences was assessed by oneway analysis of variance (ANOVA) using SPSS (PASW Statistics 23; SPSS Inc., Chicago, IL, USA). When ANOVA indicated a significant difference among groups, the difference was evaluated using the least-significant difference (LSD) test. All data are presented as mean $\pm \mathrm{SD}$, with $P<0.05$ taken to indicate significance.

\section{Results and discussion}

\section{Structural and surface characteristics}

The SEM images presented in Figure 1 show the structure and surface of the 3-D composite scaffolds fabricated by the rapid prototyping technique according to changes in the amounts of WP. As expected, the structural interconnectivity of pores was confirmed along with uniform strands. The pores were rectangular in shape and approximately $450 \mu \mathrm{m}$ in width. Pore structure is an essential consideration in tissue engineering scaffold development because it affects cell growth, migration, and nutrient flow. ${ }^{27}$ In addition to the interconnectivity of each pore, pore size is also very important in the pore structure. Many reports have suggested that the optimal pore size for bone ingrowth, cell penetration, proliferation, and differentiation is about $200-500 \mu \mathrm{m}$ in diameter. ${ }^{28-30}$ Accordingly, the m_MS/PCL/WP scaffold with its wellinterconnected pores of about $450 \mu \mathrm{m}$ in width is suitable as a bone substitute. In addition, the scaffolds proposed in this study contained m_MS, which is known to have mesoporous characteristics, and is used in the fabrication of scaffolds to provide a hierarchical structure along with macro-scale pores. The micro- and mesoporous structures of composite scaffolds enhance the surface area and surface roughness, both of which affect cell attachment. ${ }^{31}$ As shown in Figure 1, as the content of WP increased, the surface roughness of the strands of each scaffold became coarse. This may also affect cell adhesion.

\section{Hydrophilicity and mechanical stiffness}

It is generally required that scaffolds used in tissue engineering are biodegradable and biocompatible. The rate of biodegradation depends on the tissue in which it is applied. In the case of hard tissue, polymers with low degradation rates are preferred. Therefore, PCL has been widely studied. However, overcoming its hydrophobicity is one of the challenges related to use of this material. Various techniques have been introduced, such as plasma treatment 

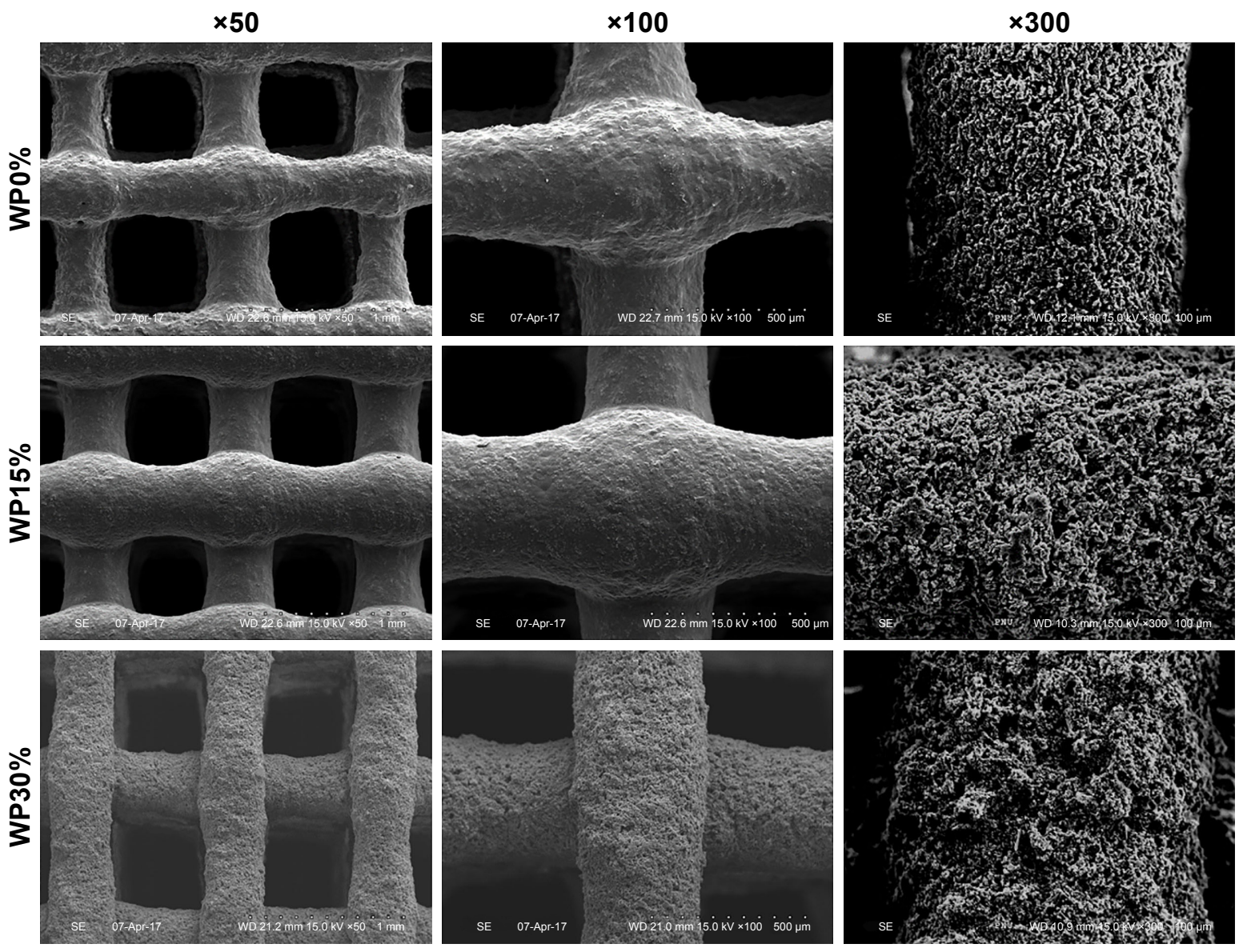

Figure I SEM images of composite scaffolds (WP0\%, $m \_M S: P C L: W P=30: 70: 0$ w/w; WPI5\%, $m \_M S: P C L: W P=30: 55: 15$ w/w; WP30\%, $m \_M S: P C L: W P=30: 40: 30$ w/w) at different magnifications $(\times 50, \times 100$, and $\times 300)$.

Abbreviations: SEM, scanning electron microscopy; m_MS:PCL:WP, mesoporous magnesium/polycaprolactone/wheat protein; WP, wheat protein; w/w, weight per weight.

or biomacromolecule immobilization, for surface modification. ${ }^{32,33}$

In this study, we attempted to increase the hydrophilicity by adding WP rather than by modifying the surface characteristics. WP is a polypeptide, and such natural polymers are generally known to be temperature-sensitive but hydrophilic. ${ }^{14}$ Contact angles were measured to evaluate the effect of WP on hydrophilicity. Specimens with higher WP content showed lower contact angles, indicating that addition of WP increased hydrophilicity (Figure 2A). First, the

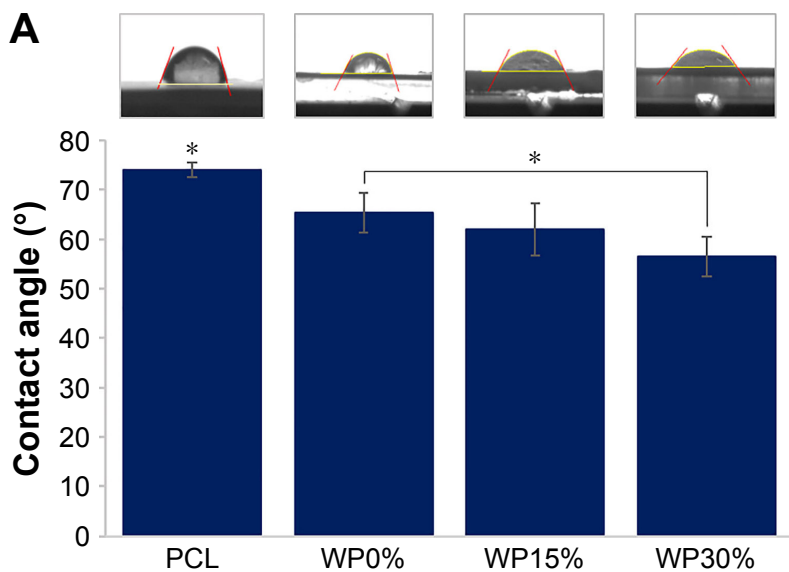

B

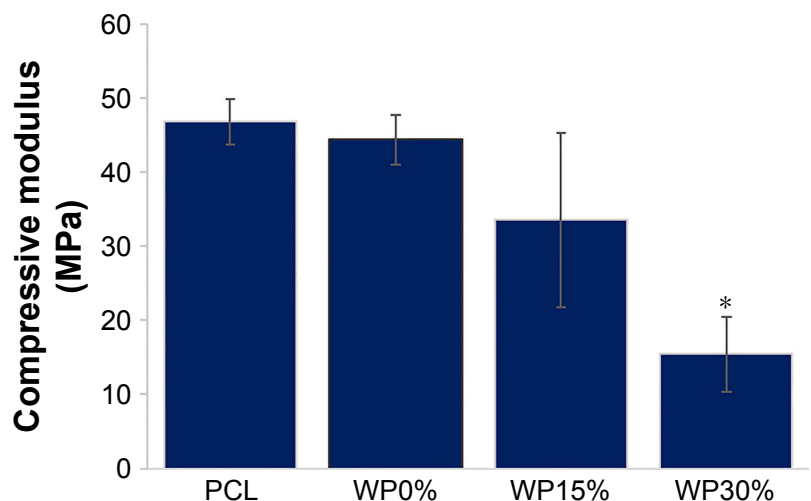

Figure 2 (A) Contact angle and (B) compressive modulus of scaffolds $(n \geq 3)$.

Note: $* P<0.05$.

Abbreviations: PCL, polycaprolactone; WP, wheat protein. 
contact angle was measured on the PCL scaffold as control and found $74.17^{\circ}$ in average, which was consistent with previously reported values of $74^{\circ}-78^{\circ}$ for PCL. ${ }^{34}$ The contact angle measured on the surface of the scaffolds added with m_MS and WP was significantly lower than that on the scaffold made only with PCL regardless of the added amounts of WP. In the groups containing m_MS and WP added, the contact angle tended to decrease as the addition amount of WP increased. Especially, the contact angle of the WP30\% group was significantly smaller than that without addition. In other words, specimens with higher WP content showed lower contact angles, indicating that addition of WP increased hydrophilicity. Therefore, it was confirmed that the m_MS affects the hydrophilicity of PCL, and addition of a certain amount of WP can increase the hydrophilicity.

Mechanical strength is also important for scaffolds used in bone tissue engineering. Compressive modulus values obtained from compression testing of the three types of scaffold and scaffolds made only with PCL are shown in Figure 2B. Both types of scaffold with PCL alone and m_MS, but without addition of WP (WP0\%), showed almost the same compressive modulus indicating that the amounts of m_MS added in this study did not affect the mechanical strength. However, as the amount of WP increased, the mechanical strength decreased markedly. The mechanical properties of the ideal scaffold for bone regeneration should be comparable to those of the host bone in tissue engineering to prevent any possible undesirable outcomes such as non-uniform load transfer and consequent biological outcomes due to so-called stress shielding. The mechanical properties of bone vary from cancellous bone to cortical bone. The compression modulus is known to be 100-200 MPa for cortical bone and 2 to $20 \mathrm{MPa}$ for cancellous bone. ${ }^{35}$ As shown in Figure $2 \mathrm{~B}$, the scaffolds containing some amounts of WP (15\% or $30 \%)$ showed comparable mechanical strength to cancellous bone. However, we did not perform the flexural tests in this study because the scaffolds suggested here were aimed for small defect in bones not for long defect, or longer than critical defect.

\section{Water absorption and in vitro degradation properties of $\mathrm{PCL} / \mathrm{m}-\mathrm{MS} / \mathrm{WP}$ scaffolds}

Water absorption capacity measurements can provide another indicator of hydrophilicity. As shown in Figure 3A, the WP30\% group showed the highest water absorption capacity, continuously, from the first day of measurement. This was consistent with the contact angle measurement results (Figure 2A), which showed that hydrophilicity was significantly increased compared to the case where WP is not added when the WP is added more than a certain proportion (WP30\% in this study) in the scaffolds.

Weight loss was measured during the same period as the water absorption test (Figure 3B), and the differences in degradation among the groups were examined. The WP30\% group showed significantly greater weight loss than the other two groups throughout the experiment. WP15\%, although containing WP, did not show any difference over the entire duration of the experiment compared to the group without any WP.

Liu et $\mathrm{al}^{36}$ reported that degradation is closely related to water absorption and/or pore distribution. The results of the water absorption test and weight loss amount, indicating degradation, were correlated. Interestingly, in both cases, the WP content had to exceed a certain amount $(30 \%$ in this study) to show a significant difference.

As described, the scaffolds proposed in this study were prepared by varying the amount of WP added to the complex of PCL and m-MS. PCL is known to have a considerably long degradation period of about 24 months. ${ }^{37}$ Sun et $\mathrm{al}^{38}$
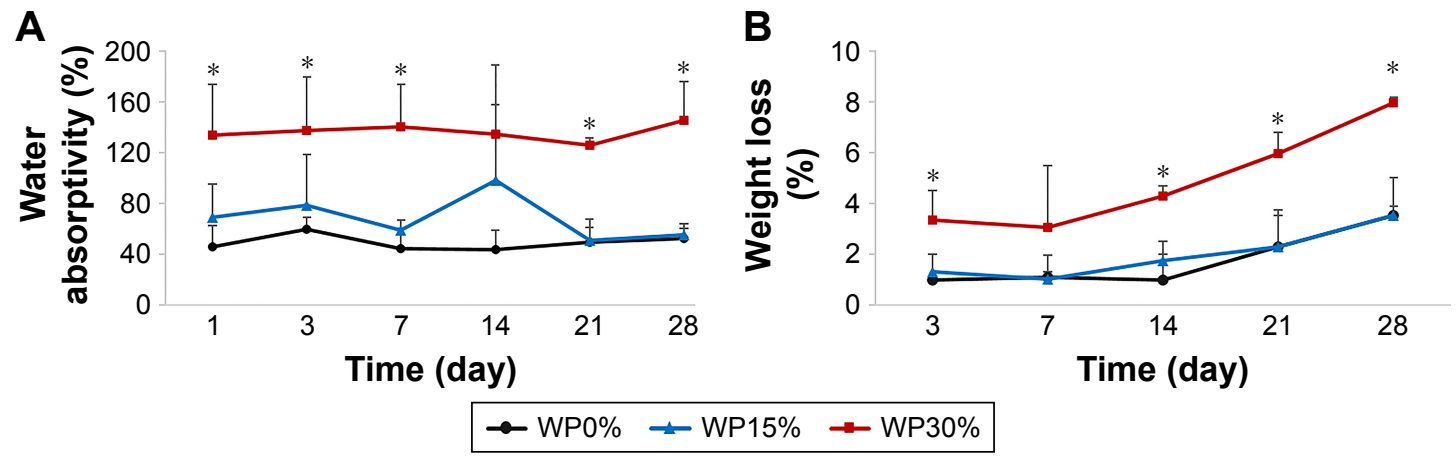

Figure 3 (A) Water absorption and (B) weight loss of $m_{-}$MS/PCL/WP scaffolds soaked in PBS for different periods ( $\left.n=3\right)$.

Note: $* P<0.05$

Abbreviation: $\mathrm{m} \_$MS/PCL/WP, mesoporous magnesium/polycaprolactone/wheat protein. 
reported the in vivo degradation of PCL for 3 years in rats. The results showed that the PCL having a molecular weight of 8,000 degraded in 30 months, and the PCL with MW 66,000 retained its shape for 2 years. In this study, PCL (MW 43,000-50,000) was used. Therefore, the degradation over 4 weeks in this study was mainly due to decomposition of WP on the surface, rather than to degradation of PCL.

Figures 1 and 4 show SEM images of WP0\%, WP15\%, and WP30\% before and after soaking in SBF for 7 days, respectively. The ability to form apatite and the amount of apatite are very important for bone tissue regeneration, which can be assessed by soaking in SBF in vitro. ${ }^{39,40}$ Before soaking in SBF, the degree of roughness differed due to m_MS and
WP, but scaffolds were generally smooth and homogenous. However, after soaking in SBF for 7 days, small particles were found on the surfaces in all groups, and it was confirmed that the surface became rougher with increasing WP content. To investigate the ability of forming apatite we ran energy dispersive spectrometry (EDS) analyses. Two major components, $\mathrm{Ca}$ and $\mathrm{P}$, were detected along with $\mathrm{C}, \mathrm{O}, \mathrm{Mg}$, and $\mathrm{Si}$. The ratio of $\mathrm{Ca}$ to $\mathrm{P}$ was ranged from 1.2-1.6, where higher value was obtained in WP30\% (data not shown). This range wash was somewhat different from the theoretical value of 1.67. However, considering that this process is going on, it is believed that the proposed scaffolds are capable of apatite formation.
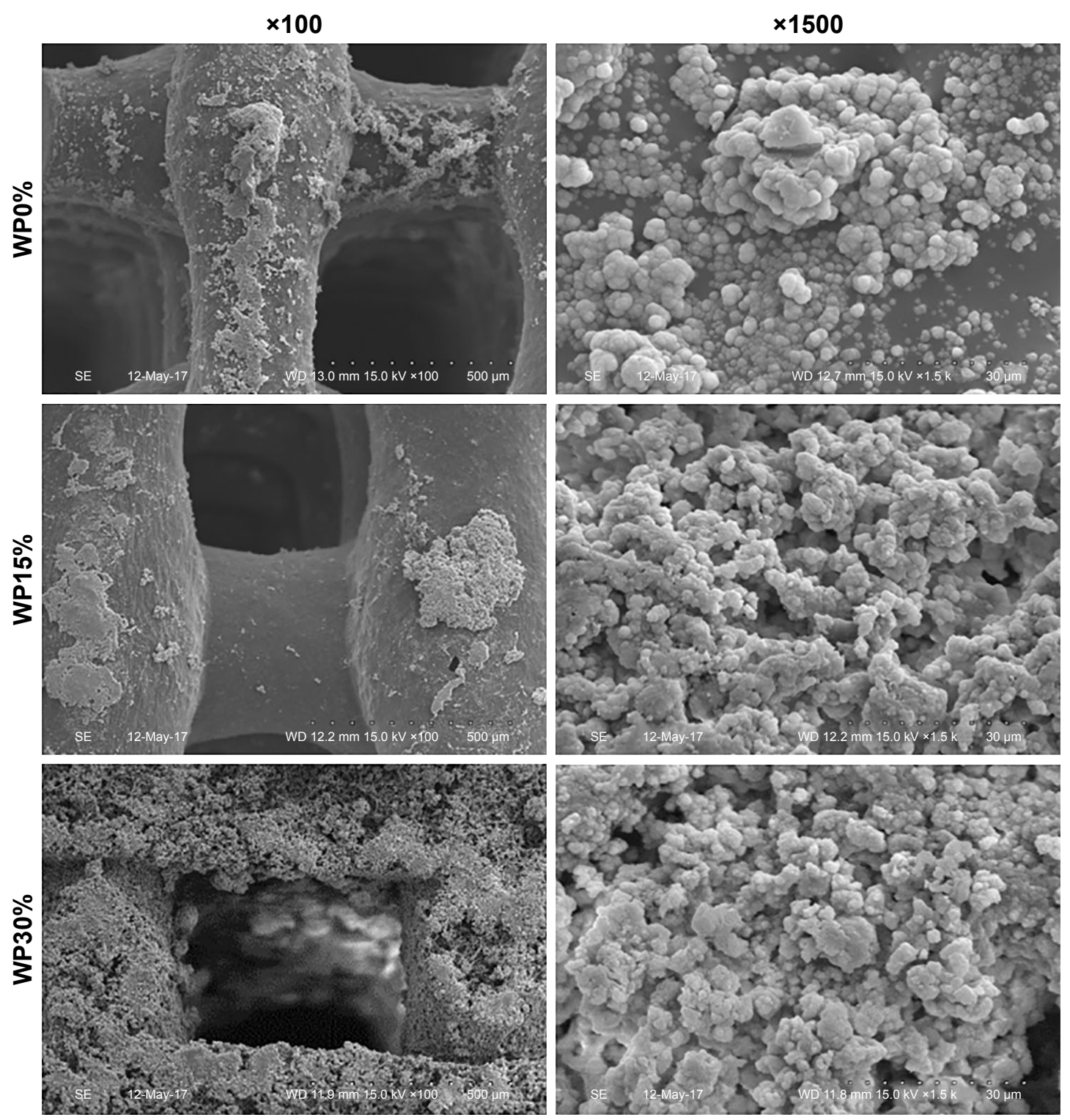

Figure 4 SEM images of the surface morphology of each scaffold (WP0\%, WPI5\%, and WP30\%) after soaking in SBF solution for 7 days at different magnifications $(\times 100$ and $\times 1500)$.

Abbreviations: SEM, scanning electron microscopy; WP, wheat protein; SBF, simulated body fluid. 


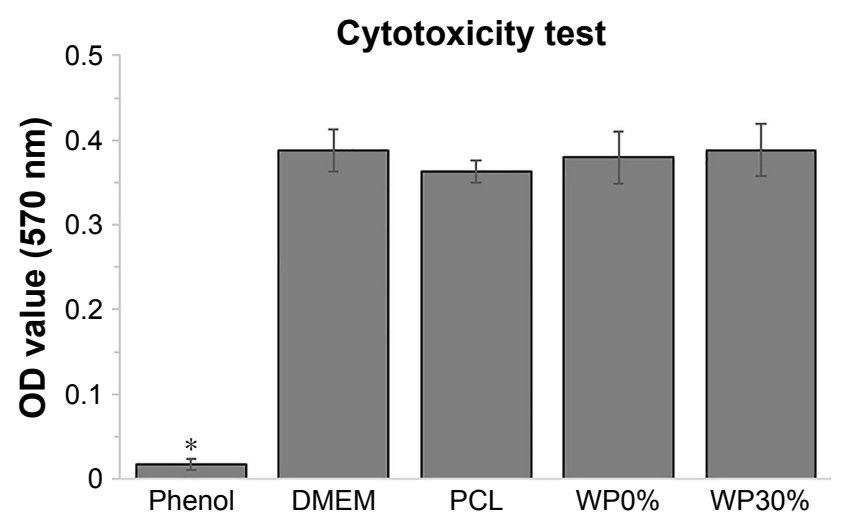

Figure 5 Cytotoxic evaluation of each scaffold with L929 mouse fibroblast-like cells in comparison with negative control (PCL extracts and DMEM alone) and positive control (dilute phenol) for $24 \mathrm{~h}(\mathrm{n} \geq 4)$.

Note: $* P<0.05$.

Abbreviation: PCL, polycaprolactone.

\section{Cytotoxicity of PCL/m-MS/WP scaffolds}

In order to confirm the cytotoxicity of each material, test for in vitro cytotoxicity tests according to ISO 10993-12 and ISO 10993-5 were conducted. Figure 5 shows the absorbance obtained from a MTT assay of L929 cells which were cultured with each extract media in comparison with those cultured with phenol (positive control), DMEM, and PCL (negative control). The MTT results showed that the group cultured with the extracts of $\mathrm{m} \_\mathrm{MS} / \mathrm{PCL}$ (WP0\% group) or $\mathrm{m} \_\mathrm{MS} / \mathrm{PCL} / \mathrm{WP}$ (WP30\% group) showed no significant difference from the negative controls (PCL and DMEM). As expected, the positive control ( $1 \%$ phenol) showed significantly lower OD values than the other groups $(P<0.05$, $n \geq 4$ ). All of the obtained results clearly suggested that scaffolds composed of m_MS, PCL, and WP were non-toxic to cells.

\section{Viability, proliferation and osteogenic differentiation of MSCs on scaffolds}

Live/dead viability assay was performed to confirm the viability and alignment of MSCs on each scaffold (Figure 6). As expected, it was confirmed that MSCs were evenly distributed and aligned to the scaffold lattice. In addition, the number of dead cells was extremely small compared to the number of live cells, and the ratio was not significantly different in all groups. From these results, it was confirmed once again that the material of each scaffold was non-toxic to cells.

The proliferation of cells cultured in each scaffold for 14 days was confirmed as shown in Figure 7. Cell proliferation gradually increased in all groups until 7 days, but there were no significant differences between the groups. However, the amount of DNA in the WP30\% group was significantly increased on day 14 compared to the other groups. These results suggested that the hydrophilic surface of WP30\% was favorable for cell adhesion and proliferation. Webb et al ${ }^{41}$ suggested that hydrophilic materials are better than hydrophobic materials for cell attachment and proliferation. These results also tended to agree with those of previous studies indicating that cell attachment and proliferation increased with increasing amounts of WP. ${ }^{14}$

ALP activity is known to be an early marker of osteogenic differentiation. ${ }^{14,28}$ Figure 8 shows ALP normalized with each DNA of MSCs on WP0\%, WP $15 \%$, and WP30\% for 7 and 14 days. Over time, ALP activity increased in all
WP0\%
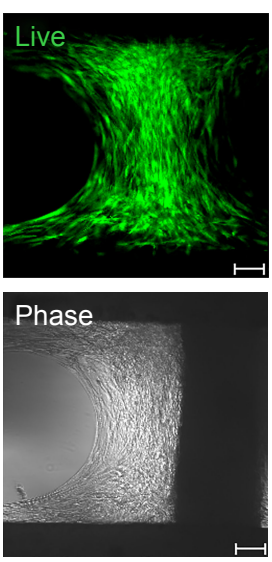
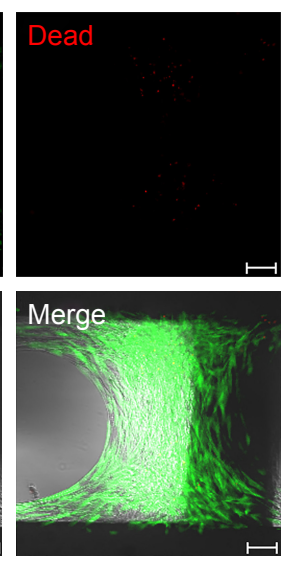

WP15\%
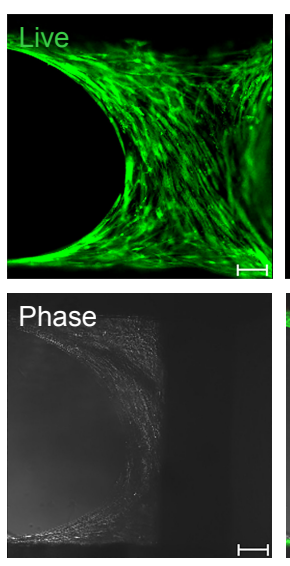
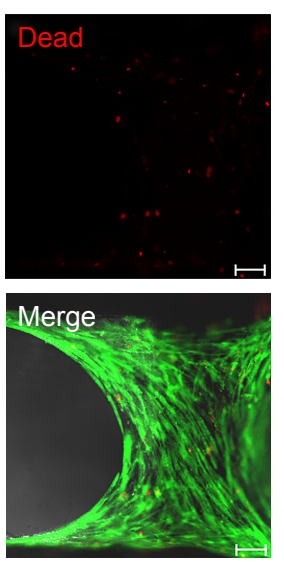

WP30\%
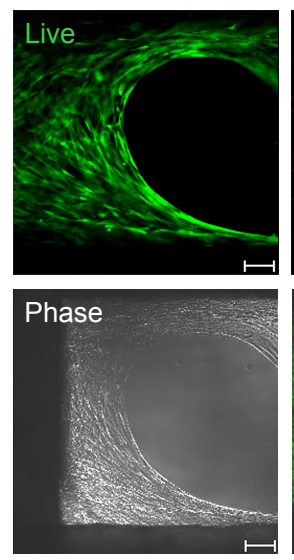

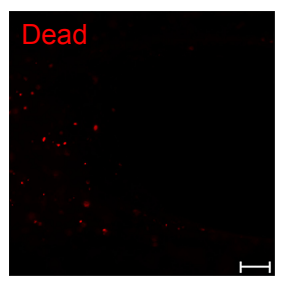

Merge

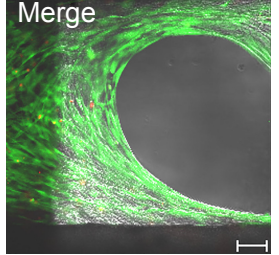

Figure 6 Confirmation of viability and cell alignment of MSCs on each scaffold using live (green)/dead (red) assay on day 7.

Notes: Magnification $\times 100$; scale bar $=100 \mu \mathrm{m}$.

Abbreviations: MSCs, mesenchymal stem cells; WP, wheat protein. 


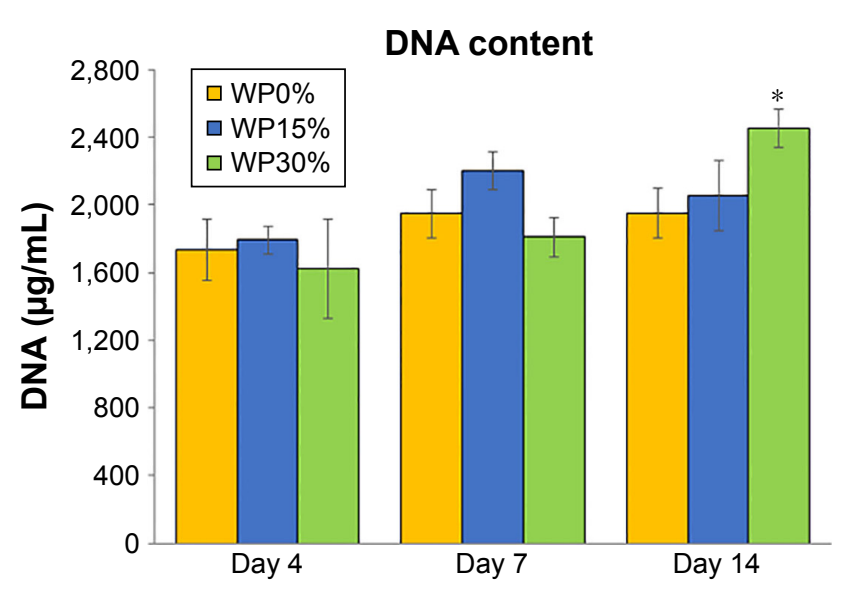

Figure 7 DNA content reflecting the proliferation of MSCs cultured on each scaffold for up to 14 days $(n=5)$.

Note: $* P<0.05$.

Abbreviations: MSCs, mesenchymal stem cells; WP, wheat protein.

groups. More specifically, ALP activity tended to increase with the WP content at day 7, but the difference was not significant. ALP activity on day 14 was significantly increased in the WP-containing groups (ie, WP15\% and WP30\%) compared to the WP-free group (WP0\%), but there was no significant difference between the former two groups according to content.

To evaluate further the osteogenic differentiation of MSCs according to the component ratio of composite materials, we performed qRT-PCR to investigate the relative gene expression of osteogenic markers, such as bone

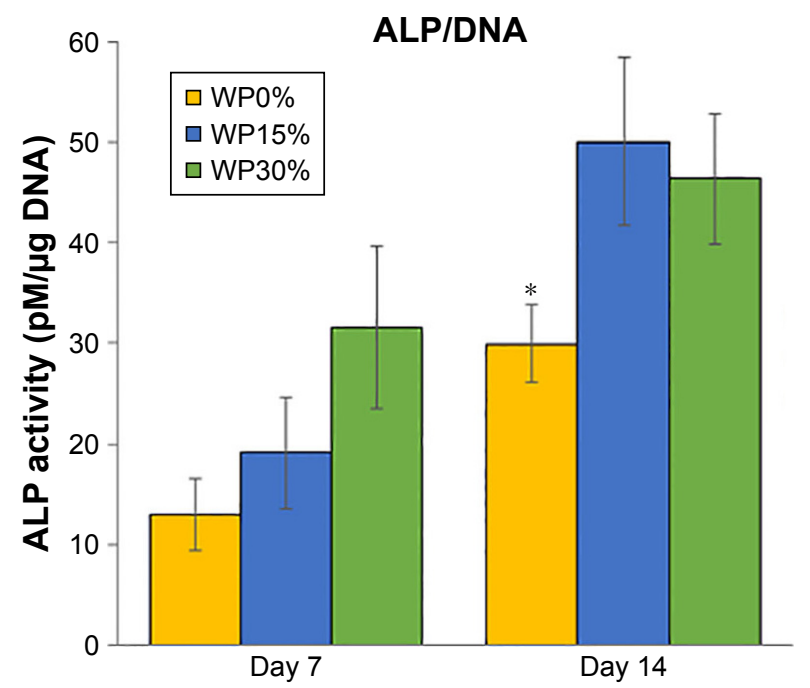

Figure 8 ALP activity of MSCs after cultivating for 7 and 14 days on each scaffold $(n=5)$.

Note: $* P<0.05$.

Abbreviations: ALP, alkaline phosphatase; MSCs, mesenchymal stem cells; WP, wheat protein. morphogenetic protein $2(B M P 2)$, bone sialoprotein $(B S P)$, collagen type 1 alpha 1 chain (COL1A1), runt-related transcription factor $2(R U N X 2)$, and osteopontin $(O P N) \cdot{ }^{42}$ After 14 days in culture, MSCs cultured on each scaffold were harvested and examined for their relative gene expression levels (Figure 9). We used MSCs (passage \#3) cultured on polystyrene tissue culture dishes with the same medium as a control group. The results indicated significantly higher expression levels of all osteogenic markers in cells cultured on composite scaffolds (WP0\%, WP15\%, and WP30\%) compared to monolayer controls on day 14 of cultivation. Kale et $\mathrm{a}^{43}$ reported that 3 -D culture improves the osteogenic differentiation of human MSCs by upregulation of several bone-related proteins, such as ALP and COL1A1. In particular, the gene expression level of all osteogenic markers was significantly increased in the groups containing WP (ie, WP15\% and WP30\%) compared to the group without WP (ie, WP0\%) and, surprisingly, the gene expression levels of most osteogenic markers were significantly higher in the WP15\% group than the WP30\% group. These results were consistent with those of previous studies indicating that the addition of WP affects the hydrophilicity and degradability of scaffolds and also affects cell attachment and proliferation of cell lines. ${ }^{14}$ In addition, we confirmed that the addition of WP and composition of composite material also affect the osteogenic differentiation of human MSCs.

\section{Conclusion}

This in vitro study was performed using a rapid prototyping technique that combined m_MS, a mineral known to provide mesopores to PCL, which are candidates for use in bone tissue engineering. Changes in physical properties and biological responses associated with the addition of a certain amount of the natural polymer, WP, were evaluated. The addition of WP increased the surface roughness and improved both hydrophilicity and degradability. However, WP was shown to decrease the mechanical strength. In cell culture experiments using MSCs, the addition of WP promoted proliferation and osteogenic differentiation of MSCs. However, further studies are needed to confirm the optimal composition ratio for obtaining good mechanical properties and osteogenic differentiation control. These data indicated that the osteogenic differentiation and bioactivity, as well as mechanical properties, hydrophilicity, and degradability by human MSCs, can be tailored through controlling the composition of $\mathrm{m} \_\mathrm{MS} / \mathrm{PCL} /$ WP. The $\mathrm{m} \_\mathrm{MS} / \mathrm{PCL} / \mathrm{WP}$ composite is a promising candidate scaffold for cell-based bone regeneration. 

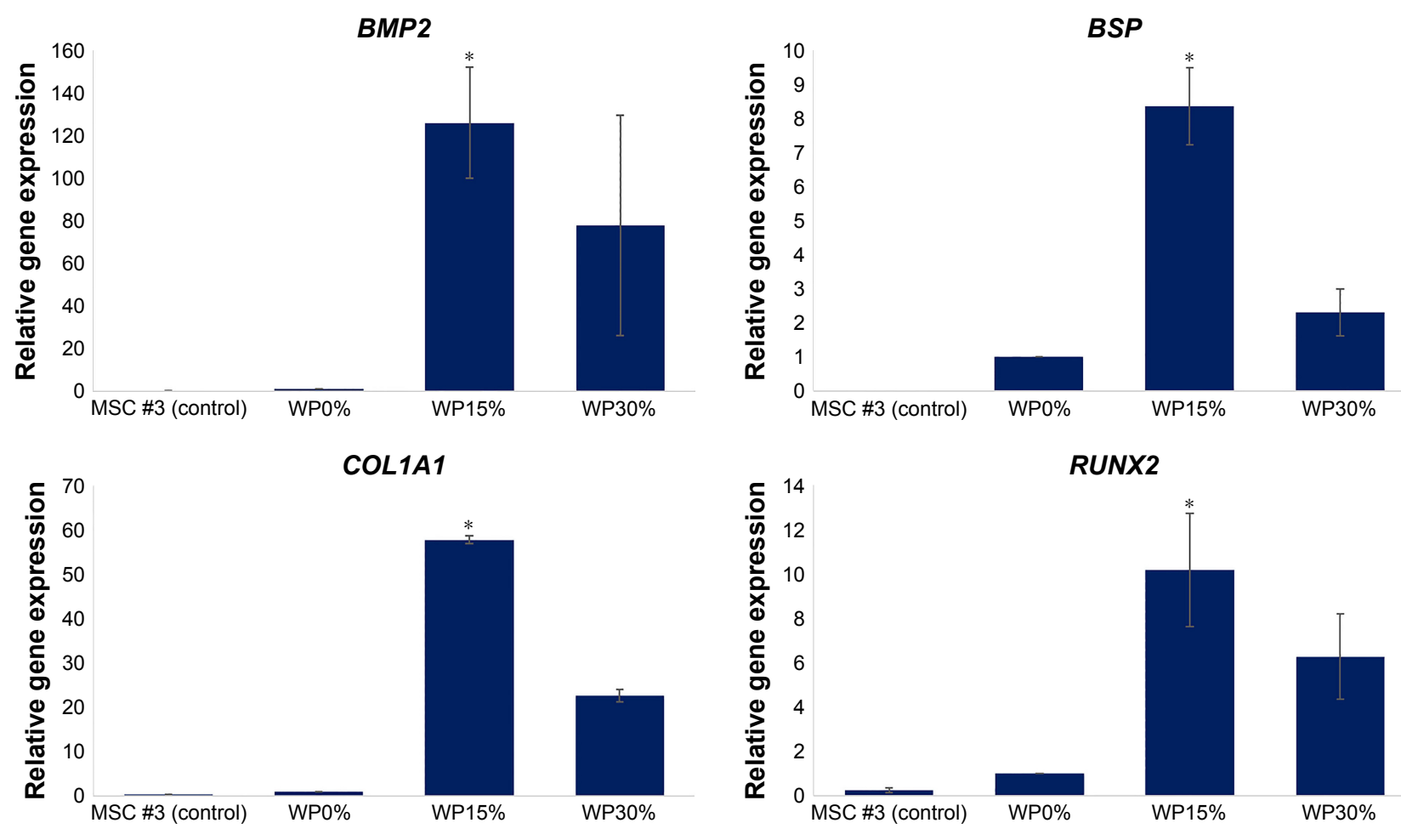

COL1A1

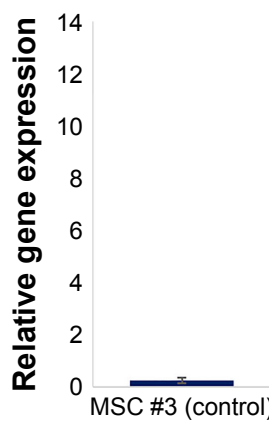

RUNX2
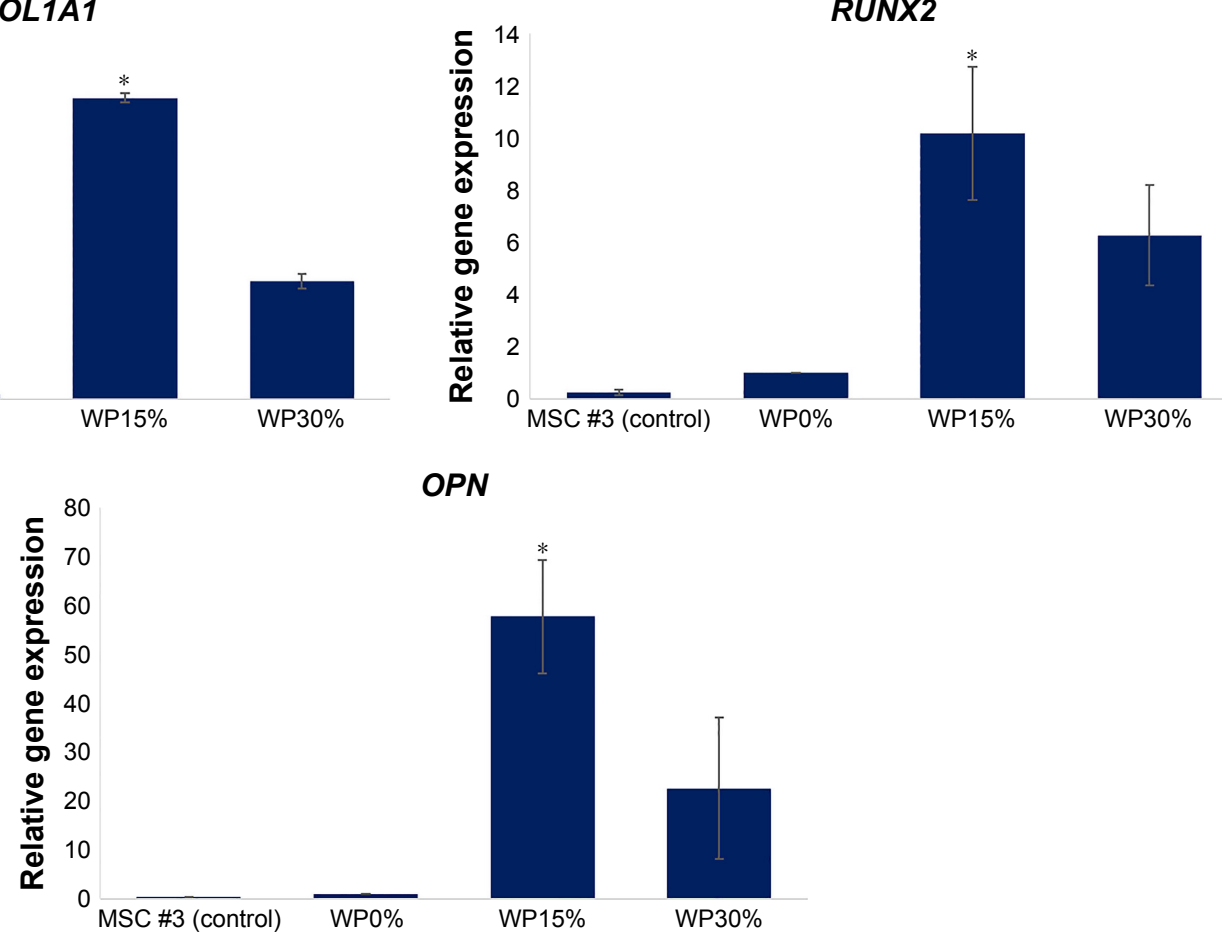

OPN

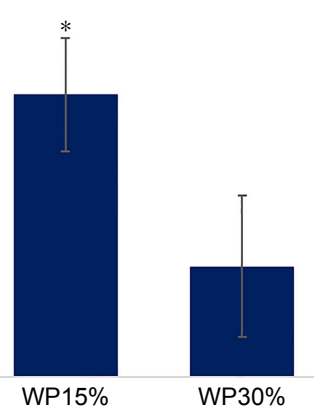

Figure 9 Gene expression levels of osteogenic markers, such as BMP2, BSP, COLIAI, RUNX2, and OPN, in MSCs cultured for 14 days ( $\mathrm{n}=3$, $* P<0.05$ ).

Abbreviations: BMP2, bone morphogenetic protein 2; BSP, bone sialoprotein; COLIAI, collagen type I alpha I chain; RUNX2, runt-related transcription factor 2; OPN, osteopontin; MSC, mesenchymal stem cells; WP, wheat protein.

\section{Acknowledgments}

This work was supported by the National Research Foundation of Korea (NRF) Grant (NRF-2014K2A2A7066637, NRF-2015M3A9B6073643). The abstract of this paper was presented at the TERMIS-EU 2017 Conference as a poster presentation with interim findings. The poster's abstract was published in "Poster Abstracts" in eCM Journal as Enhanced osteogenesis of human mesenchymal stem cells in mesoporous magnesium silicate/polycaprolactone/wheat protein composite scaffolds.

\section{Disclosure}

The authors report no conflicts of interest in this work.

\section{References}

1. Ohba S, Yano F, Chung U. Tissue engineering of bone and cartilage. IBMS Bonekey. 2009;6(11):405-419.

2. Chao PH, Grayson W, Vunjak-Novakovic G. Engineering cartilage and bone using human mesenchymal stem cells. J Orthop Sci. 2007; 12(4):398-404.

3. Yeong WY, Chua CK, Leong KF, Chandrasekaran M. Rapid prototyping in tissue engineering: challenges and potential. Trends Biotechnol. 2004;22(12):643-652.

4. Burg KJ, Porter S, Kellam JF. Biomaterial developments for bone tissue engineering. Biomaterials. 2000;21(23):2347-2359.

5. Rodrigues $C V$, Serricella $P$, Linhares $A B$, et al. Characterization of a bovine collagen-hydroxyapatite composite scaffold for bone tissue engineering. Biomaterials. 2003;24(27):4987-4997.

6. Mooney DJ, Baldwin DF, Suh NP, Vacanti JP, Langer R. Novel approach to fabricate porous sponges of poly(D,L-lactic-co-glycolic acid) without the use of organic solvents. Biomaterials. 1996;17(14):1417-1422.

7. Nam YS, Park TG. Porous biodegradable polymeric scaffolds prepared by thermally induced phase separation. J Biomed Mater Res. 1999;47(1):8-17. 
8. Nie L, Chen D, Suo J, et al. Physicochemical characterization and biocompatibility in vitro of biphasic calcium phosphate/polyvinyl alcohol scaffolds prepared by freeze-drying method for bone tissue engineering applications. Colloids Surf B Biointerfaces. 2012;100:169-176.

9. Williams JM, Adewunmi A, Schek RM, et al. Bone tissue engineering using polycaprolactone scaffolds fabricated via selective laser sintering. Biomaterials. 2005;26(23):4817-4827.

10. Zhu Y, Gao C, Shen J. Surface modification of polycaprolactone with poly(methacrylic acid) and gelatin covalent immobilization for promoting its cytocompatibility. Biomaterials. 2002;23(24):4889-4895.

11. Marra KG, Szem JW, Kumta PN, DiMilla PA, Weiss LE. In vitro analysis of biodegradable polymer blend/hydroxyapatite composites for bone tissue engineering. J Biomed Mater Res. 1999;47(3):324-335.

12. Gomes ME, Sikavitsas VI, Behravesh E, Reis RL, Mikos AG. Effect of flow perfusion on the osteogenic differentiation of bone marrow stromal cells cultured on starch-based three-dimensional scaffolds. J Biomed Mater Res A. 2003;67(1):87-95.

13. Lligadas G, Ronda JC, Galia M, Cadiz V. Renewable polymeric materials from vegetable oils: a perspective. Mater Today (Kidlington). 2013 16(9):337-343.

14. Feng S, Li J, Jiang X, et al. Influences of mesoporous magnesium silicate on the hydrophilicity, degradability, mineralization and primary cell response to a wheat protein based biocomposite. J Mater Chem B. 2016;4:6428-6436.

15. Liao L, Wang Q, Zhao MM. Investigation of the susceptibility of acid-deamidated wheat gluten to in vitro enzymatic hydrolysis using Raman spectra and free amino acid analysis. J Sci Food Agric. 2012; 92(9):1865-1873.

16. Barak S, Mudgil D, Khatkar BS. Biochemical and functional properties of wheat gliadins: a review. Crit Rev Food Sci Nutr. 2015;55(3):357-368

17. Kim S, Kim YS. Production of gliadin-poly (ethyl cyanoacrylate) nanoparticles for hydrophilic coating. J Nanopart Res. 2014;16;(2):2277.

18. Zeng R, Dietzel W, Witte F, Blawert C. Progress and challenge for magnesium alloys as biomaterials. Adv Eng Mater. 2008;10;(8):B3-B14.

19. Staiger MP, Pietak AM, Huadmai J, Dias G. Magnesium and its alloys as orthopedic biomaterials: a review. Biomaterials. 2006;27(9):1728-1734

20. Diba M, Tapia F, Boccaccini AR, Strobel LA. Magnesium-containing bioactive glasses for biomedical applications. Int J Appl Glass Sci. 2012; 3(3):221-253.

21. Brown A, Zaky S, Ray H, Sfeir C. Porous magnesium/PLGA composite scaffolds for enhanced bone regeneration following tooth extraction. Acta Biomater. 2015;11:543-553.

22. Yoshizawa S, Brown A, Barchowsky A, Sfeir C. Magnesium ion stimulation of bone marrow stromal cells enhances osteogenic activity, simulating the effect of magnesium alloy degradation. Acta Biomater. 2014; 10(6):2834-2842.

23. He D, Dong W, Tang S, et al. Tissue engineering scaffolds of mesoporous magnesium silicate and poly( $\varepsilon$-caprolactone)-poly(ethylene glycol)-poly(ع-caprolactone) composite. J Mater Sci Mater Med. 2014; 25(6):1415-1424.

24. Wu C, Chen Z, Wu Q, et al. Clinoenstatite coatings have high bonding strength, bioactive ion release, and osteoimmunomodulatory effects that enhance in vivo osseointegration. Biomaterials. 2015;71:35-47.

25. Shi X, Wang Y, Ren L, Zhao N, Gong Y, Wang D-A. Novel mesoporous silica-based antibiotic releasing scaffold for bone repair. Acta Biomater. 2009;5(5):1697-1707.
26. Vallet-Regí M. Ordered mesoporous materials in the context of drug delivery systems and bone tissue engineering. Chemistry. 2006;12(23): 5934-5943.

27. Karageorgiou V, Kaplan D. Porosity of 3D biomaterial scaffolds and osteogenesis. Biomaterials. 2005;26(27):5474-5491.

28. Heo SJ, Kim SE, Wei J, et al. In vitro and animal study of novel nano-hydroxyapatite/poly(epsilon-caprolactone) composite scaffolds fabricated by layer manufacturing process. Tissue Eng Part A. 2009; 15(5):977-989.

29. Pamula E, Bacakova L, Filova E, et al. The influence of pore size on colonization of poly(L-lactide-glycolide) scaffolds with human osteoblast-like MG 63 cells in vitro. JMater Sci Mater Med. 2008;19(1): 425-435.

30. Oh SH, Park IK, Kim JM, Lee JH. In vitro and in vivo characteristics of PCL scaffolds with pore size gradient fabricated by a centrifugation method. Biomaterials. 2007;28(9):1664-1671.

31. Kuhn P, Forget A, Su D, Thomas A, Antonietti M. From microporous regular frameworks to mesoporous materials with ultrahigh surface area: dynamic reorganization of porous polymer networks. J Am Chem Soc. 2008;130(40):13333-13337.

32. Martins A, Pinho ED, Faria S, et al. Surface modification of electrospun polycaprolactone nanofiber meshes by plasma treatment to enhance biological performance. Small. 2009;5(10):1195-1206.

33. Zhu Y, Gao C, Liu X, Shen J. Surface modification of polycaprolactone membrane via aminolysis and biomacromolecule immobilization for promoting cytocompatibility of human endothelial cells. Biomacromolecules. 2002;3(6):1312-1319.

34. Tiaw KS, Goh SW, Hong M, Wang Z, Lan B, Teoh SH. Laser surface modification of poly(epsilon-caprolactone) (PCL) membrane for tissue engineering applications. Biomaterials. 2005;26(7):763-769.

35. Bose S, Roy M, Bandyopadhyay A. Recent advances in bone tissue engineering scaffolds. Trends Biotechnol. 2012;30(10):546-554.

36. Liu YS, Huang QL, Kienzle A, Müller WE, Feng QL. In vitro degradation of porous PLLA/pearl powder composite scaffolds. Mater Sci Eng C Mater Biol Appl. 2014;38:227-234.

37. Lu Y, Chen SC. Micro and nano-fabrication of biodegradable polymers for drug delivery. Adv Drug Deliv Rev. 2004;56(11):1621-1633.

38. Sun H, Mei L, Song C, Cui X, Wang P. The in vivo degradation, absorption and excretion of PCL-based implant. Biomaterials. 2006;27(9): $1735-1740$

39. Niu Y, Guo L, Liu J, et al. Bioactive and degradable scaffolds of the mesoporous bioglass and poly (L-lactide) composite for bone tissue regeneration. J Mater Chem B. 2015;3:2962-2970.

40. Cao L, Weng W, Chen X, et al. Development of degradable and bioactive composite as bone implants by incorporation of mesoporous bioglass into poly (L-lactide). Compos Part B Eng. 2015;77:454-461.

41. Webb K, Hlady V, Tresco PA. Relative importance of surface wettability and charged functional groups on NIH $3 \mathrm{~T} 3$ fibroblast attachment, spreading, and cytoskeletal organization. J Biomed Mater Res. 1998; 41(3):422-430.

42. Frank O, Heim M, Jakob M, et al. Real-time quantitative RT-PCR analysis of human bone marrow stromal cells during osteogenic differentiation in vitro. $J$ Cell Biochem. 2002;85(4):737-746.

43. Kale S, Biermann S, Edwards C, Tarnowski C, Morris M, Long MW. Three-dimensional cellular development is essential for ex vivo formation of human bone. Nat Biotechnol. 2000;18(9):954-958.
International Journal of Nanomedicine

\section{Publish your work in this journal}

The International Journal of Nanomedicine is an international, peerreviewed journal focusing on the application of nanotechnology in diagnostics, therapeutics, and drug delivery systems throughout the biomedical field. This journal is indexed on PubMed Central, MedLine, CAS, SciSearch $®$, Current Contents $\AA /$ Clinical Medicine,

\section{Dovepress}

Journal Citation Reports/Science Edition, EMBase, Scopus and the Elsevier Bibliographic databases. The manuscript management system is completely online and includes a very quick and fair peer-review system, which is all easy to use. Visit http://www.dovepress.com/ testimonials.php to read real quotes from published authors. 